\title{
Toxicogenomics for the Prediction of Toxicity Related to Herbs from Traditional Chinese Medicine
}

Authors

Affiliations
Mahmoud Youns ${ }^{1,3}$, Jörg D. Hoheisel ${ }^{2}$, Thomas Efferth ${ }^{1}$

${ }^{1}$ Department of Pharmaceutical Biology, Institute of Pharmacy and Biochemistry, University of Mainz, Mainz, Germany

2 Functional Genome Analysis, German Cancer Research Centre (DKFZ), Heidelberg, Germany

${ }^{3}$ Department of Biochemistry, Faculty of Pharmacy, University of Helwan, Ain Helwan, Cairo, Egypt
Key words

toxicogenomics

traditional Chinese medicine

- microarray

- medicinal herbs received Feb. 5, 2010

revised Sept. 14, 2010

accepted Sept. 20,2010

Bibliography

DOI http://dx.doi.org/

10.1055/s-0030-1250432

Published online October 18,

2010

Planta Med 2010; 76:

2019-2025 @ Georg Thieme

Verlag KG Stuttgart · New York ·

ISSN 0032-0943

Correspondence

Prof. Thomas Efferth

Department of

Pharmaceutical Biology

Institute of Pharmacy

and Biochemistry

University of Mainz

Staudinger Weg 5

55128 Mainz

Germany

Phone: + 4961313925751

Fax: + 4961313923752

efferth@uni-mainz.de

\section{Abstract}

$\nabla$

Toxicogenomics represents the integration of genomics and toxicology to investigate the interaction between genes and environmental stress in human health. It is a scientific field that studies how the genome is involved in responses to environmental stressors and toxicants. The patterns of altered gene expression that are caused by specific exposures or disease outcomes reveal how toxicants may act and cause disease. Nowadays, toxicogenomics faces great challenges in discriminating the molecular basis of toxicity. We do believe that advances in this field will eventually allow us to describe all the toxicological interactions that occur within a living system. Toxicogenomic responses of a toxic agent in one species (e.g., laboratory animals) may predict the mode of action in another species (e.g., humans) (predictive toxicology). Development and application of toxicogenomic databases and new bioinformatics tools

\section{Introduction}

$\nabla$

Toxicogenomics is a scientific field aiming to understand the interaction between the genome, toxic chemicals in the environment, and disease. If cells or organisms are exposed to xenobiotic compounds, they respond by altering the pattern of expression of genes. Genes are transcribed into mRNA, and the chemical information encoded in genes is translated into proteins that serve a variety of cellular functions in response to the exposure. Depending upon the type of exposure and the cellular response, the production of protein encoded by a given gene may be increased, decreased, or remains unchanged. Toxicogenomics can be used to predict adverse toxic effects of toxic compounds on susceptible individuals. This usually involves using "-omics" techniques such as DNA microarray, protein microarray, single- are among the most important aspects of toxicogenomic research which will facilitate sharing and interpretation of the huge amount of biological information generated in this field. Medicinal herbs have played an important role in pharmacy from ancient to modern times. Nowadays, there is a revival of interest in medicinal plants and an increasing scientific interest in bioactive natural products. Medicinal herbs are usually considered to be nontoxic. However, the consumption of herbs could produce prominent toxic effects either due to inherent toxicity or to contaminants (heavy metals, microorganisms, pesticides, toxic organic solvents, radioactivity, etc.). Therefore, a critical assessment of their toxicity is an urgent issue. This review explores the field of toxicogenomics, pinpoints some of its research approaches and describes the challenges it faces. In particular, Chinese herbal preparations have been implicated.

nucleotide polymorphism analysis of genetic variations of individuals, etc. Such studies are then correlated to adverse toxicological effects in clinical trials for developing suitable diagnostic biomarkers [1].

Even though natural products are regarded as "gentle medicines", there are some exceptions; not only contamination might cause toxicity, but also the addition of wrong and poisonous herbs can be a major health problem [2]. For instance, in the 1990s, incidences of poisoning by aristolochic acids were reported in European countries where herbal mixtures for slimming erroneously included the poisonous plant Aristolochia fangchi, which contains the nephrotoxic and carcinogenic aristolochic acids [3,4]. These compounds, after metabolic activation, form DNA adducts that lead to gene mutation [5]. The reason for such intoxication by aristolochic acid was that some plant 
species in different regions of China have very similar names. The name "fang ji" is used in some parts of China for the plant Stephania tetrandra (han fang ji), which is the correct constituent of the herbal slimming mixture, whereas the same name in other regions of China is used for the plant Aristolochia fangchi (guang fang ji), which was mistaken for Stephania tetrandra [2].

The ability to identify mechanisms of toxicity of environmental toxicants or toxic contaminants of medicinal herbs is an important challenge to protect human health. In addition, problems of identifying environmental factors involved in the etiology of human disease and of performing safety assessments for drugs and chemicals have long been formidable issues [6].

Toxicology is defined as the study of poisons and focuses on any substance and/or exposures that cause adverse toxic effects in living organisms. A vital part of this study is the contextual characterization of such adverse effects at the level of the whole organism, tissues, cells, and intracellular molecular systems [7]. Recently, the rapid accumulation of genomic sequence data and associated gene and protein annotation has catalyzed the application of gene expression analysis to understand the molecular modes of action of chemicals and other environmental stressors on biological systems [6]. These developments have facilitated the emergence of the field of toxicogenomics, which aims to study the response of a whole genome to toxicants or to other environmental stressors [8-13]. The related field of toxicoproteomics [14-16] is similarly defined with respect to the protein subset of the genome. Global technologies such as cDNA and oligonucleotide microarrays, protein chips, and nuclear magnetic resonance (NMR)-based molecular profiling, respectively, can simultaneously measure the expression of numerous genes, proteins, and metabolites, thus providing the power to accelerate the discovery of mechanisms of action, toxicant pathways, and specific chemical and drug molecular targets [17-19]. Hence, toxicogenomics combines toxicology with genetics, global “-omics" technologies, and appropriate pharmacological and toxicological models to provide a comprehensive view of the function of the genetic and biochemical machinery of cells [6].

The goal of this review is to report recent progress in the development and application of toxicogenomics, to share some experience with the use of toxicogenomics in drug discovery and development, and to provide our perspective on its value as a mechanistic tool for the study and prediction of adulterations of medicinal plants derived from traditional Chinese medicine.

\section{Toxicogenomics in Drug Development}

$\nabla$

The early prediction of possible side effects that occur in clinical use with new drugs can be used for assessing their safety before time- and cost-consuming clinical studies. In an effort to develop drugs with less adverse effects, the National Institute of Health Sciences (NIH) in collaboration with 17 pharmaceutical companies started a collaborative project in 2002 to elucidate interrelationships between toxicants and gene expression [20]. About 150 chemicals were administered to rats and/or human primary cultured hepatocytes, and the expression profiles in the liver and kidney of animals or in cultured hepatocytes were comprehensively analyzed by microarrays. A database was created with the accumulated genomic information to generate a tool for predicting the safety of candidate chemicals in an early stage of drug de- velopment [20]. The three principal goals of toxicogenomics are to interpret the relationship between environmental stressors, drugs, and human disease susceptibility, to identify useful biomarkers of disease and exposure to toxic substances, and to elucidate the molecular mechanisms governing toxicity [6].

In traditional drug development, pharmaceutical companies evaluate the toxic effects of drugs through preclinical studies, including acute toxicity, safety pharmacology, and reproductive toxicity, to ensure the safety of new drugs before administration to humans. However, it is practically impossible to completely avoid unexpected side effects in clinical use. Moreover, it has been observed that unexpected adverse effects first emerged even after the drugs were distributed in the market because of their low incidence in small-scale clinical trials [20]. The field of toxicogenomics in the NIH project has the aim to detect toxic effects of drug candidates by “-omics" technologies at an early time point in the drug development process [13].

\section{Toxicogenomics Methods \\ $\nabla$}

A typical toxicogenomic study might consist of animal experiments with the following four groups: high-dose and low-dose treatment groups, a vehicle control group that has received only the solvent used with the test agent, and another control group that has received no treatment and no solvent (to control the solvent effect). These groups will be observed at two or three points in time, with a minimum of five animal subjects per group. In this respect, a toxicogenomic investigation resembles a traditional, acute toxicity study. The high-dose and low-dose approaches differ in the scope of the response they aim to detect and in the methods used.

In a typical toxicogenomic experiment, differentially expressed genes are created for each biological test sample in comparison to the control sample [21]. Differentially regulated genes can be subjected to signalling pathway analyses to identify signal transduction routes of toxic effects and to identify candidate genes of interest [21]. Relevant knowledge systematically extracted and assembled from microarray data can then be used to differentiate between the adaptive responses of biological systems and biomarkers that are associated with adverse effects in the clinical setting [22]. During the past decade, the concept of gene expression profiles as signatures of toxicant classes, disease subtypes, or other biological and clinical end points has been validated [6]. These signatures have directed the analytical search for predictive biomarkers of toxicant effects and contributed to the understanding of the dynamic alterations in molecular mechanisms that are associated with toxic and adaptive responses [6].

A shortcut to test the toxicity towards specific organs in various organ systems in the adult organism or to measure embryo-toxicity is that large numbers of animals are required. As an alternative, stem cell lines represent a feasible proposition to reduce animal experiments. Using stem cell lines, efforts are being made to standardize protocols for preclinical toxicology in the field of drug development [23]. Stem cells are a valuable tool for toxicogenomic approaches using medicinal herbs derived from traditional Chinese medicine (TCM). 


\section{Advances in Chemical and Biological Screening of Herbal Poisoning \\ $\nabla$}

Recent technological innovations allow mRNA profiling of formalin-fixed tissues and potentially make archived tissues from generations of toxicological studies accessible to gene-expression analysis [24]. Nowadays, gas chromatography, liquid chromatography, mass spectrometry, DNA microarray, and protein array are among the methods that can be used to profile thousands of small molecules and to array thousands of toxicologically relevant protein antibodies in a high-throughput mode. In addition to their application in the screening of herbal poisoning, chromatography and spectroscopy have been used to study chemical compositions of Chinese medicinal plants and complex herbal mixtures. Using ultraviolet spectroscopy (UV), gas chromatography (GC), high-performance liquid chromatography (HPLC), Raman spectroscopy, infrared spectroscopy (IR), nuclear magnetic resonance spectroscopy (NMR), mass spectroscopy (MS), GC-MS, HPLC-MS, and X-ray diffraction, many chemical compounds from Chinese medicinal herbs have been isolated and identified. Recently, capillary electrophoresis has been used to deduce the botanical sources and to assess the quality of Ephedrae Herba [25], Paeoniae Radix [26], Coptidis Rhizoma [27] and Ginseng Radix [28]. Coupling HPLC or GC with other analytical systems has increased the sensitivity of such techniques. For instance, the combination of liquid chromatography and tandem mass spectrometry was efficient to detect coeluting closely related substances [29] and to quantify active components from traditional Chinese medicine over a concentration range of $1 \mathrm{ng} /$ $\mathrm{mL}$ to $10 \mu \mathrm{g} / \mathrm{mL}$ [30]. In TCM, synergistic actions provided by some chemically unknown or not isolated ingredients in compound prescriptions have proven effective from double-blind clinical trials. Thus these analytical methods alone may not be appropriate for quality and efficacy assurance [31].

In addition to the fact that some of the instruments such as HPLC, capillary electrophoresis, and mass spectrometry are expensive and may not generally be available in analytical laboratories, chemical methods usually require large amounts of samples for a proper analysis. Classical cytogenetic methods including karyotyping and chromosome counting may also be used to differentiate medicinal materials and play a role in assessing hybridity of plants [31]. DNA molecules are trustable biological markers for informative polymorphisms as the genetic composition is unique for each individual and is less affected by physiological conditions, age, as well as environmental factors. Nuwaysir et al. [32] generalized the term "toxicogenomics" to describe the use of microarrays to measure the responses of genes, and to identify selective, sensitive biomarkers of toxicity. The first published toxicogenomic investigation compared the gene expression profiles of human cells responding to the allergen lipopolysaccharide with those responding to mitogenic activation by phorbol myristate acetate [33]. RNA samples, isolated at various time points after exposure, showed the expected increases in cytokine, chemokine, and matrix metalloproteinase transcripts. Similar gene expression profiles were seen in synoviocytes and chondrocytes from a patient with rheumatoid arthritis, confirming the ability of the system to mimic the biological changes that occur during inflammatory disease [33]. Subsequent studies extended this type of observation to other tissues and for a wide range of toxicants, enabling the association of specific molecular profiles with specific toxicities [6].
DNA marker detection may also be appropriate for toxicological screening of Chinese medicinal herbs and products, as most TCM products are combinations of multiple herbs. Advantages of DNA markers include: (1) small amounts of samples are sufficient for analysis; and (2) the physical form of the sample for assessment does not restrict detection. DNA can be extracted from stems, leaves, or roots of herbal materials. Therefore, DNA fingerprinting is a very powerful tool to assess and confirm the plant species of complex herbal mixtures in order to exclude adulterations.

\section{Traditional Chinese Medicine with Toxic Contaminants} $\nabla$

TCM is becoming more and more popular in western countries [31]. Whilst problems relating to the toxicity of their herbal ingredients have been previously reported [31], safety issues for TCM products on the market have frequently not been appropriately addressed. Adulterations of TCM products with conventional drugs, toxic organic solvents, heavy metals, pesticides, microbial contaminations or even radioactivity represent considerable quality control issues ( Fig. 1 ). Toxicogenomics may provide a tool for quality assurance, if TCM products should be marketed on a worldwide scale.

Diagnosis of a serious illness such as cancer is among the most stressful experiences of modern life [34]. In addition to standard treatments of western "school" medicine, the majority of cancer patients seek complementary measures, sometimes with, sometimes without the knowledge of their treating physicians [3537]. In East Asia, patients often try to enhance their general health by taking herbal remedies [37]. The reasons why cancer patients use TCM are heterogeneous. Some authorities claim weak scientific evidence for the efficacy of TCM [38]. Only a minority of cancer patients expects that TCM will exert specific and curative anticancer activity $[39,40]$, even though certain herbs, e.g., Codonopsis (dang shen), Coix (yi yi ren), and Gynostemma (jiao gu lan) are claimed to possess such efficacy towards liver cancer [41]. Rather, many cancer patients expect that TCM will improve disease symptoms or decrease side effects of conventional cancer therapies [42]. This point of view is indeed substantialted by clinical trials showing the benefit of supplementing conventional chemo- and radiotherapy by TCM $[43,44]$. Among the most frequent reasons claimed by patients for taking TCM preparations is to enhance general health or "vital energy" ( $q i)$ by restoring "balance" (yin/yang) [45], to individualize an otherwise standard treatment plan (especially in breast and gynecologic cancer patients) [46], to detoxify or strengthen immunity [47], to reduce the adverse effects of conventional anticancer treatments [48], to use a treatment modality that is less harmful than standard therapies [49], to regain a sense of control over a life-threatening disorder $[50,51]$, or to offset the noncurative goals of "scientific" palliative treatments and, thus, to help accept the inevitability of death $[35,52]$. Complementary medicines have been reported in one study to be used more frequently by cancer patients who believe they will die within one year [53]. This speaks for a kind of psychological support that many patients may obtain from TCM and other unconventional therapies. Certain TCM-derived drugs, such as the antimalarial artemisinin (from the herb Artemisia annua [qing haosu]) have been scientifically proven to have therapeutic efficacy [54-56]. Other TCM-derived herbs may offer benefits such as myeloprotection (e.g., improvement of chemotherapy-induced cytopenias by the putative 


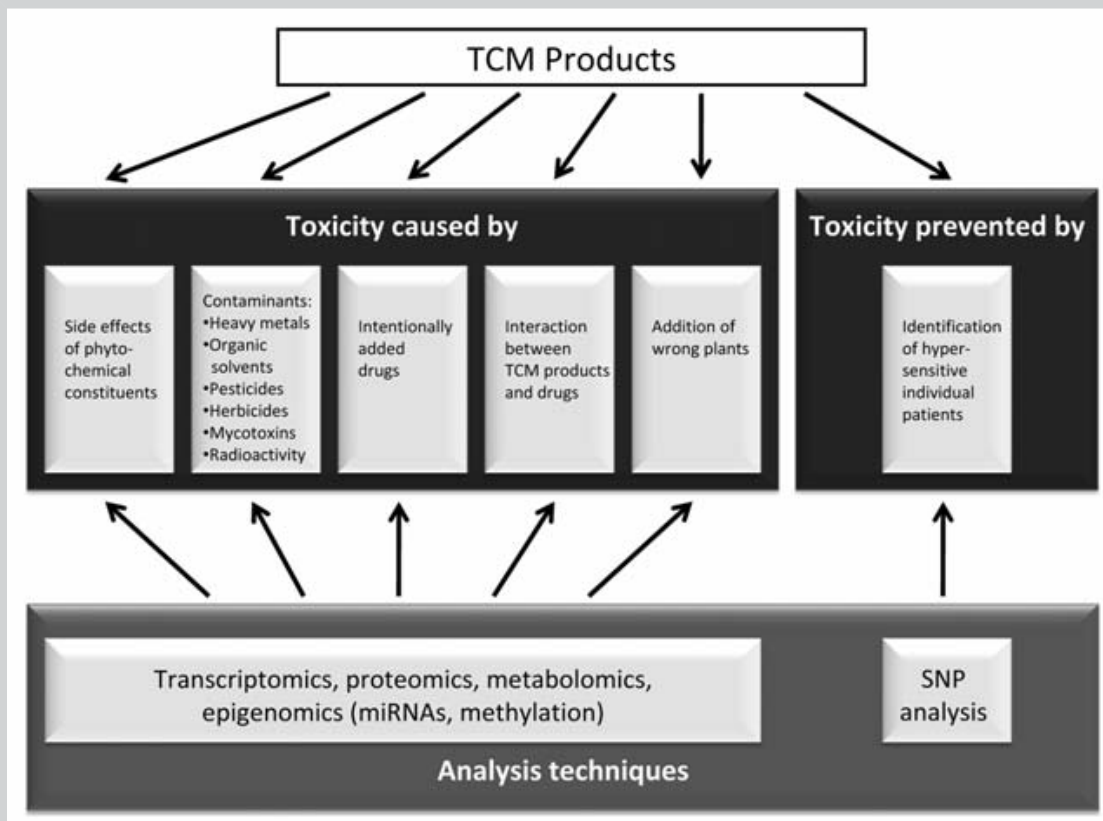

Fig. 1 A framework for TCM products showing the most common causes of toxicity and some "-omics" analysis tools that can be used to identify a specific signature for each toxicant.

toxin-cleaning herb Oldenlandia), gut mucosal protection (e.g., prevention of irinotecan-induced diarrhea by Scutellaria), antiemesis, hepatoprotection, neuroprotection, or nephroprotection. However, convincing evidence for both efficacy and safety is frequently weak $[35,57]$. However, it should be noted that active natural products reveal both wanted and unwanted effects in rational cancer therapy and the combined application of the genomic, proteomic, and metabolomic technologies will improve the overall understanding of mechanisms of toxicity and disease.

\section{Mechanisms of TCM Toxicity and Interactions} $\nabla$

Most xenobiotic compounds including phytochemicals are metabolized and detoxified in the liver by the hepatic P450 cytochrome system. For example, aristolochic acid is metabolized by CYP1A2, whereas CYP3A4 interactions are influenced by pyrrolizidine alkaloids [58]. Interactions between TCM products and conventional drugs may involve interaction with cytotoxic drugs, medications being administered for symptomatic indications, or drugs taken for disorders such as hypertension or diabetes. Such drug interactions are the most frequent causes of TCM-dependent clinical complications [59]. Moreover, intentional or accidental contamination of TCM preparations with impurities, heavy metals, or bacteria is another source of clinical problems. Intentional adulteration of TCM with bioactive additives such as corticosteroids, hormones, salicylates, or antihistamines is yet another cause of toxicity. In addition, immunoallergic TCM responses are common and microbial reactivation of diseases such as tuberculosis or viruses (HBV, HCV, VZ) can also occur [35].

Heavy metals are among the major contaminants of TCM. Numerous case reports of heavy metal poisoning associated with the use of TCM have been reported [60]. Lead, for example, has always been implicated as a source of poisoning through administration of TCM products. Mercury, arsenic, cadmium, thallium, and copper have also been found in TCM remedies [60]. Californian officials have screened for unidentified pharmaceuticals, adulterations, and heavy metals in imported Chinese remedies on sale in Californian herbal retail stores [61]. Out of the 251 products tested, $7 \%$ contained undeclared pharmaceuticals (e.g., chlorpheniramine, ephedrine, phenacetin, and methyltestosterone). Sixty-three contained an average of $14.6 \mathrm{ppm}$ arsenic; 24 products contained at least $10 \mathrm{ppm}$ lead; 35 contained an average of 1046 ppm mercury; and 23 had more than one contaminant and/or adulterant. In addition to the previously mentioned analysis, Koh and Woo [62] reported the detection of heavy metal toxicity that exceeded the legal limits of Singapore in 42 Chinese herbal medicines among approximately 2080 Chinese medicine samples collected in Singapore and screened for their heavy metal content. Mercury was found in 28 products, lead in eight, arsenic in six and copper in one. One product contained both mercury and lead and another product contained both mercury and arsenic [63].

Melchart et al. [64] screened 317 batches of dried Chinese herbs delivered to a German hospital of Chinese medicine. They reported that $3.5 \%$ of these samples contained heavy metals beyond the legal limits. Herbette et al. [65] investigated the transcriptional regulation in response to cadmium treatment in both roots and leaves of Arabidopsis, using the whole genome microarray containing at least 24576 independent probe sets. Arabidopsis plants were treated with low $(5 \mu \mathrm{M})$ or high $(50 \mu \mathrm{M})$ cadmium concentrations during 2, 6, and 30 hours. Analyses of response profiles demonstrated the existence of a regulatory network that differentially modulates gene expression in a tissueand kinetic-specific manner in response to cadmium [65]. Moreover, using microarray slides containing 7000-9000 genes, Koizumi et al. [66] studied the gene expression profiles of a human cervical carcinoma cell line, HeLa S3, exposed to Cadmium (Cd). They reported that by exposure to a nonlethal concentration of Cd, 46 upregulated and 10 downregulated genes whose expression levels changed twofold or more were observed. The expression of genes related to cellular protection and damage control mechanisms such as those encoding metallothioneins, antioxidant proteins, and heat shock proteins was simultaneously induced. In addition, altered expression of many genes involved in signalling, metabolism, and so on was newly described. When 
cells were exposed to a higher concentration of $\mathrm{Cd}$, more remarkable effects were observed both in the number of affected genes and in the extent of altered expression [66]. We believe that by using microarray gene expression profiling studies, we may be able to identify a signature for each metal poison, based on the specific gene expression changes, and these signatures could then be used to detect trace metal poisoning in TCM and/or other herbal preparations.

Several possibilities could explain the presence of heavy metals in TCM remedies: (1) Heavy metals could be added intentionally for expected medicinal properties. Some Indian schools of medicine emphasize the importance of metals such as lead, gold, iron, copper, mercury, tin, silver, and zinc for the proper function of the human body [63]. Ayurvedic textbooks mentioned the toxicity of heavy metals and recommended special physicochemical processes that, according to ancient Indian belief, would detoxify such toxic heavy metals, e.g., by heating them until they glow [67]. In TCM, mercury is part of some preparations under the terminology of "cinnabaris" (mercury sulfide), "calomel" (mercury chloride), or "hydrargyri oxydum rubrum" (mercury oxide). Such preparations are used for a variety of indications, for example, as a tranquillizer, an antiepileptic, for ulcers, or to treat insomnia [62]. Lead is used as Mi Tuo Seng (Lithargyrum) [68] and arsenic as Xiong Huang (Realgar) in the manufacturing of several TCMs [68]. These constituents are, thus, not contaminants, but ingredients intentionally included for a specific medical purpose; (2) The presence of heavy metal contaminants in TCM remedies could be the result of contamination during manufacturing, either from grinding weights or lead-increasing containers or other manufacturing utensils [62]; and (3) Heavy metals might be present when Chinese herbs were grown on seriously polluted soil $[63,69]$. Moreover, it is relevant to note that TCMs might also contain animal and mineral products which might be contaminated with heavy metals [70].

Obviously, heavy metals are not the only possible source for toxic ingredients in Chinese herbal remedies. Mycotoxins from microorganisms, herbicides, pesticides, insects, or undeclared herbal constituents represent other relevant contaminations [71-73]. In addition, contamination with toxic herbal constituents, which may be introduced through misidentification of the herbal ingredients, can be a serious problem. In Belgium, the use of a TCM product contaminated with plant material from Aristolochia (fangchi) resulted in an epidemic subacute intestinal nephropathy. Many of the affected patients required kidney transplantation. Histopathological examination of surgically removed kidneys and urethras from those patients showed conclusive signs of neoplasms in $40 \%$ of cases [74]. Numerous case reports originating from countries such as Australia, Belgium, China, The Netherlands, New Zealand, UK, and USA demonstrate adulterations of TCM products with synthetic drugs and associate the use of adulterated herbal medicines with health problems of users [63]. The resulting clinical findings are mostly serious and sometimes life-threatening. Moreover, Cushing's syndrome, agranulocytosis, and coma have been reported. Comparable analyses are available for Chinese herbal medicines collected in Australia, Taiwan, and UK [63,75-77]. The largest of these studies is that of Huang and colleagues from Taiwan [75], who showed that $24 \%$ of all 2609 samples collected contained at least one adulterant. Other clinical cases were also reported [78,79].

Approximately half of the patients using complementary herbal medicines do not inform their doctors [80], which further increases health risks, because physicians might fail to diagnose ad- verse effects caused by treatments of which they are not notified. Moreover, people taking herbal remedies mostly combine them with conventional drugs [80]. This opens the possibility of herbdrug interactions [81,82], which, in turn, further raises concerns about consumers' safety and underlines an urgent need for improved toxicogenomics tools.

\section{The Future of Toxicogenomics}

$\nabla$

The etiology of various chronic diseases and poisonings involves interactions between environmental factors, chemicals, and genes that modulate physiological processes. Toxicogenomic approaches will provide insights into the molecular mechanisms of chemical actions, diseases, toxicity, and therapeutic drug interactions. These insights could be provided by toxicogenomic databases by integrating data describing relationships between chemicals, genes, proteins, and human diseases [83]. In the context of TCM, toxicogenomics will help not only to detect trace amounts of contaminants in TCM remedies by providing specific gene expression signatures which are characteristic for specific contaminants, but also will facilitate understanding their molecular mode of toxic action in the human body.

Toxicogenomics integrates multiple data derived from transcriptomics, proteomics, and metabonomics with traditional toxicological and histopathological evaluation. This integration will improve the understanding of the relationship between toxicological outcomes and molecular genetics [13]. A prerequisite for the evolution of a predictive toxicology, in which the knowledge of toxicogenomic responses of an agent in one species (e.g., laboratory animals) could be used to predict the mode of action of a similar agent in related or different species (e.g., human beings), is that the results of various toxicogenomics investigations should be assimilated into multigenomic knowledge databases, which should be easily searchable [6].

In addition to toxicogenomics, toxicoproteomic research will lead to the identification, measurement, and evaluation of proteins and other biomarkers that might be more sensitive, accurate, and specific than those available nowadays. Metabonomics research will also help to identify alterations at the level of small endogenous molecules and their associated pathways. Such metabolite fingerprints might then help to diagnose and define the ways in which specific xenobiotics, environmental pollutants, or contaminated TCM products cause diseases or poisonings. This, combined with the ability to detect damage to particular organs by observing alterations in serum and urine components and histopathological examinations, is expected to lead to the more sensitive detection of harmful risk factors [84]. Other considerations that should be included in assessing the toxicogenomic response to xenobiotics and contaminated TCM products are the individual genotype, exposure history, age, and lifestyle $[6,85]$.

Toxicogenomics will help to discover the modes of action of both contaminated and noncontaminated complex herbal mixtures. Moreover, it will improve our understanding to the unique genetic characters of certain species and population subgroups that make them susceptible to toxicants $[86,87]$. The combined application of the genomic, proteomic, and metabolomic technologies will improve the overall understanding of mechanisms of toxicity and disease [86]. 


\section{Conclusion and Perspectives}

$\nabla$

Recent advances in technologies and molecular sciences have enabled the interpretation of complex networks and cellular pathways at the genomic, proteomic, and metabolomic levels in response to treatment with conventional drugs, environmental pollutants, or contaminated TCM products. The promise of toxicogenomics is to provide deeper insights into the molecular action of different classes of toxicants by analyzing gene and/or protein expression profiles. The further development of bioinformatics and biostatistics will be necessary to refine pathways distinguishing the effect of large sets of agents representing a broad range of toxic effects. The goal of this review is to report recent progress in the development and application of toxicogenomics and to provide our perspective on its value as a sophisticated tool for the study and prediction of toxicity of TCM. In general, evidence suggests that toxicogenomics should improve quality control of TCM products and risk assessment.

\section{References}

1 Taylor CF. Standards for reporting bioscience data: a forward look. Drug Discov Today 2007; $12: 527-533$

2 Efferth T, Li PC, Konkimalla VS, Kaina B. From traditional Chinese medicine to rational cancer therapy. Trends Mol Med 2007; 13: 353-361

3 Nortier JL, Martinez MC, Schmeiser HH, Arlt VM, Bieler CA, Petein M, Depierreux MF, De Pauw L, Abramowicz D, Vereerstraeten P, Vanherweghem JL. Urothelial carcinoma associated with the use of a Chinese herb (Aristolochia fangchi). N Engl J Med 2000; 342: 1686-1692

4 Arlt VM, Stiborova M, Schmeiser HH. Aristolochic acid as a probable human cancer hazard in herbal remedies: a review. Mutagenesis 2002; 17: 265-277

5 Arlt VM, Alunni-Perret V, Quatrehomme G, Ohayon P, Albano L, Gaid H, Michiels JF, Meyrier A, Cassuto E, Wiessler M, Schmeiser HH, Cosyns JP. Aristolochic acid (AA)-DNA adduct as marker of AA exposure and risk factor for AA nephropathy-associated cancer. Int J Cancer 2004; 111: 977-980

6 Waters MD, Fostel JM. Toxicogenomics and systems toxicology: aims and prospects. Nat Rev Genet 2004; 5: 936-948

7 Mattes WB, Pettit SD, Sansone SA, Bushel PR, Waters MD. Database development in toxicogenomics: issues and efforts. Environ Health Perspect 2004; 112: 495-505

8 Aardema MJ, MacGregor JT. Toxicology and genetic toxicology in the new era of "toxicogenomics": impact of "-omics" technologies. Mutat Res 2002; 499: 13-25

9 Ulrich R, Friend SH. Toxicogenomics and drug discovery: will new technologies help us produce better drugs? Nat Rev Drug Discov 2002; 1 : 84-88

10 Fielden MR, Zacharewski TR. Challenges and limitations of gene expression profiling in mechanistic and predictive toxicology. Toxicol Sci 2001; 60: 6-10

11 Hamadeh HK, Amin RP, Paules RS, Afshari CA. An overview of toxicogenomics. Curr Issues Mol Biol 2002; 4: 45-56

12 Thomas RS, Rank DR, Penn SG, Zastrow GM, Hayes KR, Pande K, Glover E, Silander T, Craven MW, Reddy JK, Jovanovich SB, Bradfield CA. Identification of toxicologically predictive gene sets using cDNA microarrays. Mol Pharmacol 2001; 60: 1189-1194

13 Waters M, Boorman G, Bushel P, Cunningham M, Irwin R, Merrick A, Olden K, Paules R, Selkirk J, Stasiewicz S, Weis B, Van Houten B, Walker N, Tennant $R$. Systems toxicology and the Chemical Effects in Biological Systems (CEBS) knowledge base. EHP Toxicogenomics 2003; 111: 1528

14 Merrick BA, Tomer KB. Toxicoproteomics: a parallel approach to identifying biomarkers. Environ Health Perspect 2003; 111: A578-A579

15 Petricoin EF, Rajapaske V, Herman EH, Arekani AM, Ross S, Johann D, Knapton A, Zhang J, Hitt BA, Conrads TP, Veenstra TD, Liotta LA, Sistare $F D$. Toxicoproteomics: serum proteomic pattern diagnostics for early detection of drug induced cardiac toxicities and cardioprotection. Toxicol Pathol 2004; 32 (Suppl. 1): 122-130

16 Wilkins MR, Pasquali C, Appel RD, Ou K, Golaz O, Sanchez JC, Yan JX, Gooley AA, Hughes G, Humphery-Smith I, Williams KL, Hochstrasser DF. From proteins to proteomes: large scale protein identification by two- dimensional electrophoresis and amino acid analysis. Biotechnology (NY) 1996; 14: 61-65

17 Youns M, Efferth T, Reichling J, Fellenberg K, Bauer A, Hoheisel JD. Gene expression profiling identifies novel key players involved in the cytotoxic effect of Artesunate on pancreatic cancer cells. Biochem Pharmacol 2009; 78: 273-283

18 Youns M, Fu YJ, Zu YG, Kramer A, Konkimalla VB, Radlwimmer B, Sultmann $H$, Efferth $T$. Sensitivity and resistance towards isoliquiritigenin, doxorubicin and methotrexate in $\mathrm{T}$ cell acute lymphoblastic leukaemia cell lines by pharmacogenomics. Naunyn Schmiedebergs Arch Pharmacol 2010; 382: 221-234

19 Pinto-Garcia L, Efferth T, Torres A, Hoheisel JD, Youns M. Berberine inhibits cell growth and mediates caspase-independent cell death in human pancreatic cancer cells. Planta Med 2010; 76: 1155-1161

20 Gomase VS, Tagore S. Toxicogenomics. Curr Drug Metab 2008; 9: 250 254

21 Hamadeh HK, Knight BL, Haugen AC, Sieber S, Amin RP, Bushel PR, Stoll R, Blanchard K, Jayadev S, Tennant RW, Cunningham ML, Afshari CA, Paules $R S$. Methapyrilene toxicity: anchorage of pathologic observations to gene expression alterations. Toxicol Pathol 2002; 30: 470-482

22 Zweiger G. Knowledge discovery in gene-expression-microarray data: mining the information output of the genome. Trends Biotechnol 1999; 17: 429-436

23 Ahuja YR, Vijayalakshmi V, Polasa K. Stem cell test: a practical tool in toxicogenomics. Toxicology 2007; 231: 1-10

24 Lewis F, Maughan NJ, Smith V, Hillan K, Quirke P. Unlocking the archivegene expression in paraffin-embedded tissue. J Pathol 2001; 195: 6671

25 Liu YM, Sheu SJ, Chiou SH, Chang HC, Chen YP. A comparative study of commercial samples of Ephedrae Herba. Planta Med 1993; 59: 376378

26 Chuang WC, Lin WC, Sheu SJ, Chiou SH, Chang HC, Chen YP. A comparative study on commercial samples of the roots of Paeonia vitchii and $P$. lactiflora. Planta Med 1996; 62: 347-351

27 Liu YM, Sheu SJ, Chiou SH, Chang SH, Chen YP. Capillary electrophoretic analysis of alkaloids in commercial samples of Coptidis Rhizoma. Phytochem Anal 1994; 5: 256-260

28 Chuang WC, Wu HK, Sheu SJ, Chiou SH, Chang HC, Chen YP. A comparative study on commercial samples of Ginseng Radix. Planta Med 1995; 61: 459-465

29 Covey TR, Lee ED, Henion JD. High-speed liquid chromatography/tandem mass spectrometry for the determination of drugs in biological samples. Anal Chem 1986; 58: 2453-2460

30 Han J, Ye M, Xu M, Sun J. Wang B, Guo D. Characterization of flavonoids in the traditional Chinese herbal medicine-Huangqin by liquid chromatography coupled with electrospray ionization mass spectrometry. J Chromatogr B Anal Technol Biomed Life Sci 2007; 848: 355-362

31 Chan $K$. Some aspects of toxic contaminants in herbal medicines. Chemosphere 2003; 52: 1361-1371

32 Nuwaysir EF, Bittner M, Trent J, Barrett JC, Afshari CA. Microarrays and toxicology: the advent of toxicogenomics. Mol Carcinog 1999; 24: 153-159

33 Heller RA, Schena M, Chai A, Shalon D, Bedilion T, Gilmore J, Woolley DE, Davis RW. Discovery and analysis of inflammatory disease-related genes using cDNA microarrays. Proc Natl Acad Sci USA 1997; 94: 2150-2155

34 Holmes TH, Rahe RH. The Social Readjustment Rating Scale. J Psychosom Res 1967; 11: 213-218

35 Chiu J, Yau T, Epstein RJ. Complications of traditional Chinese/herbal medicines (TCM)-a guide for perplexed oncologists and other cancer caregivers. Support Care Cancer 2009; 17: 231-240

36 Yates JS, Mustian KM, Morrow GR, Gillies LJ, Padmanaban D, Atkins JN, Issell B, Kirshner JJ, Colman LK. Prevalence of complementary and alternative medicine use in cancer patients during treatment. Support Care Cancer 2005; 13: 806-811

37 Boon HS, Olatunde F, Zick SM. Trends in complementary/alternative medicine use by breast cancer survivors: comparing survey data from 1998 and 2005. BMC Womens Health 2007; 7: 4

38 Guo R, Canter PH, Ernst E. A systematic review of randomised clinical trials of individualised herbal medicine in any indication. Postgrad Med J 2007; 83: 633-637

39 McCulloch M, See C, Shu XJ, Broffman M, Kramer A, Fan WY, Gao J, Lieb W, Shieh K, Colford Jr JM. Astragalus-based Chinese herbs and platinumbased chemotherapy for advanced non-small-cell lung cancer: metaanalysis of randomized trials. J Clin Oncol 2006; 24: 419-430 
40 Senthilnathan P, Padmavathi R, Banu SM, Sakthisekaran D. Enhancement of antitumor effect of paclitaxel in combination with immunomodulatory Withania somnifera on benzo(a)pyrene induced experimental lung cancer. Chem Biol Interact 2006; 159: 180-185

41 Shu X, McCulloch M, Xiao H, Broffman M, Gao J. Chinese herbal medicine and chemotherapy in the treatment of hepatocellular carcinoma: a meta-analysis of randomized controlled trials. Integr Cancer Ther 2005; 4: 219-229

42 Deng G, Cassileth BR, Yeung KS. Complementary therapies for cancer-related symptoms. J Support Oncol 2004; 2: 419-429

43 Cho WC, Chen HY. Clinical efficacy of traditional Chinese medicine as a concomitant therapy for nasopharyngeal carcinoma: a systematic review and meta-analysis. Cancer Invest 2009; 27: 334-344

44 Yang YF, Ge JZ, Wu Y, Xu Y, Liang BY, Luo L, Wu XW, Liu DQ Zhang X, Song $F X$, Geng ZY. Cohort study on the effect of a combined treatment of traditional Chinese medicine and Western medicine on the relapse and metastasis of 222 patients with stage II and III colorectal cancer after radical operation. Chin J Integr Med 2008; 14: 251-256

45 Ernst $E$. The role of complementary and alternative medicine in cancer. Lancet Oncol 2000; 1: 176-180

46 Kimby CK, Launso L, Henningsen I, Langgaard H. Choice of unconventional treatment by patients with cancer. J Altern Complement Med 2003; 9: 549-561

47 Correa-Velez I, Clavarino A, Eastwood H. Surviving, relieving, repairing, and boosting up: reasons for using complementary/alternative medicine among patients with advanced cancer: a thematic analysis. J Palliat Med 2005; 8: 953-961

48 Gerber B, Scholz C, Reimer T, Briese V, Janni W. Complementary and alternative therapeutic approaches in patients with early breast cancer: a systematic review. Breast Cancer Res Treat 2006; 95: 199-209

49 Shumay DM, Maskarinec G, Kakai H, Gotay CC. Why some cancer patients choose complementary and alternative medicine instead of conventional treatment. J Fam Pract 2001; 50: 1067

50 Nahleh Z, Tabbara IA. Complementary and alternative medicine in breast cancer patients. Palliat Support Care 2003; 1: 267-273

51 Singh H, Maskarinec G, Shumay DM. Understanding the motivation for conventional and complementary/alternative medicine use among men with prostate cancer. Integr Cancer Ther 2005; 4: 187-194

52 White $M$, Verhoef $M$. Cancer as part of the journey: the role of spirituality in the decision to decline conventional prostate cancer treatment and to use complementary and alternative medicine. Integr Cancer Ther 2006; 5: 117-122

53 Hlubocky FJ, Ratain MJ, Wen M, Daugherty CK. Complementary and alternative medicine among advanced cancer patients enrolled on phase I trials: a study of prognosis, quality of life, and preferences for decision making. J Clin Oncol 2007; 25: 548-554

54 Efferth T. Mechanistic perspectives for 1,2,4-trioxanes in anti-cancer therapy. Drug Resist Updat 2005; 8: 85-97

55 Efferth T, Olbrich A, Bauer R. mRNA expression profiles for the response of human tumor cell lines to the antimalarial drugs artesunate, arteether, and artemether. Biochem Pharmacol 2002; 64: 617-623

56 Efferth T, Sauerbrey A, Olbrich A, Gebhart E, Rauch P, Weber HO, Hengstler $J G$, Halatsch ME, Volm M, Tew KD, Ross DD, FunkJO. Molecular modes of action of artesunate in tumor cell lines. Mol Pharmacol 2003; 64: 382394

57 Tagliaferri $M$, Cohen I, Tripathy D. Complementary and alternative medicine in early-stage breast cancer. Semin Oncol 2001; 28: 121-134

58 Zhou SF, Xue CC, Yu XQ Wang G. Metabolic activation of herbal and dietary constituents and its clinical and toxicological implications: an update. Curr Drug Metab 2007; 8: 526-553

59 Meijerman I, Beijnen JH, Schellens JH. Herb-drug interactions in oncology: focus on mechanisms of induction. Oncologist 2006; 11: 742-752

60 Ernst E, Thompson Coon J. Heavy metals in traditional Chinese medicines: a systematic review. Clin Pharmacol Ther 2001; 70: 497-504

61 Ko RJ. Adulterants in Asian patent medicines. N Engl J Med 1998; 339: 847

62 Koh HL, Woo SO. Chinese proprietary medicine in Singapore: regulatory control of toxic heavy metals and undeclared drugs. Drug Saf 2000; 23: 351-362

63 Ernst E. Toxic heavy metals and undeclared drugs in Asian herbal medicines. Trends Pharmacol Sci 2002; 23: 136-139
64 Melchart D, Wagner H, Hager S, Saller R, Ernst E. Quality assurance and evaluation of Chinese medicinal drugs in a hospital of traditional Chinese medicine in Germany: a five-year report. Altern Ther Health Med 2001; 7: S24

65 Herbette S, Taconnat L, Hugouvieux V, Piette L, Magniette ML, Cuine S, Auroy P, Richaud P, Forestier C, Bourguignon J, Renou JP, Vavasseur A, Leonhardt $N$. Genome-wide transcriptome profiling of the early cadmium response of Arabidopsis roots and shoots. Biochimie 2006; 88: 1751-1765

66 Koizumi S, Yamada H. DNA microarray analysis of altered gene expression in cadmium-exposed human cells. J Occup Health 2003; 45: 331334

67 Prpić-Majić D, Pizent A, Jurasović J, Pongracić J, Restek-Samarzija N. Lead poisoning associated with the use of Ayurvedic metal-mineral tonics. Clin Toxicol 1996; 34: 417-423

68 Thatte UM, Rege NN, Phatak SD, Dahanukar SA. The flip side of Ayurveda. J Postgrad Med 1993; 39: 179-182, 182a-182b

69 Palchetti I, Mascini M, Minunni M, Bilia AR, Vincieri FF. Disposable electrochemical sensor for rapid determination of heavy metals in herbal drugs. J Pharm Biomed Anal 2003; 32: 251-256

70 Chuang IC, Chen KS, Huang YL, Lee PN, Lin TH. Determination of trace elements in some natural drugs by atomic absorption spectrometry. Biol Trace Elem Res 2000; 76: 235-244

71 Slifman NR, Obermeyer WR, Aloi BK, Musser SM, Correll Jr WA, Cichowicz $S M$, Betz JM, Love LA. Contamination of botanical dietary supplements by Digitalis lanata. N Engl J Med 1998; 339: 806-811

72 Halt M. Moulds and mycotoxins in herb tea and medicinal plants. Eur J Epidemiol 1998; 14: 269-274

73 Brandao MG, Freire N, Vianna-Soares CD. [Surveillance of phytotherapeutic drugs in the state of Minas Gerais. Quality assessment of commercial samples of chamomile]. Cad Saude Publica 1998; 14: 613-616

74 Cosyns JP, Jadoul M, Squifflet JP, Wese FX, van Ypersele de Strihou C. Urothelial lesions in Chinese herb nephropathy. Am J Kidney Dis 1999; 33: 1011-1017

75 Huang WF, Wen KC, Hsiao ML. Adulteration by synthetic therapeutic substances of traditional Chinese medicines in Taiwan. J Clin Pharmacol 1997: 37: 344-350

76 Keane FM, Munn SE, du Vivier AW, Taylor NF, Higgins EM. Analysis of Chinese herbal creams prescribed for dermatological conditions. BMJ 1999; 318: 563-564

77 Keane FM, Munn SE, Vivier AW, Higgins EM, Taylor NF. Analysis of Chinese herbal creams prescribed for dermatological conditions. West J Med 1999; 170: 257-259

78 Li AM, Chan MH, Leung TF, Cheung RC, Lam CW, Fok TF. Mercury intoxication presenting with tics. Arch Dis Child 2000; 83: 174-175

79 Goudie AM, Kaye JM. Contaminated medication precipitating hypoglycaemia. Med J Aust 2001; 175: 256-257

80 Eisenberg DM, Davis RB, Ettner SL, Appel S, Wilkey S, Van Rompay M, Kessler RC. Trends in alternative medicine use in the United States, 1990-1997: results of a follow-up national survey. JAMA 1998; 280: 1569-1575

81 Ernst E. Possible interactions between synthetic and herbal medicinal products. Part 1: a systematic review of the indirect evidence. Perfusion 2000; 13: 4-6, 8

82 Ernst $E$. Interactions between synthetic and herbal medicinal products. Part 2: a systematic review of the direct evidence. Perfusion 2000; 13 : 60-70

83 Mattingly CJ, Rosenstein MC, Davis AP, Colby GT, Forrest Jr JN, Boyer JL. The comparative toxicogenomics database: a cross-species resource for building chemical-gene interaction networks. Toxicol Sci 2006; 92: 587-595

84 Wetmore BA, Merrick BA. Toxicoproteomics: proteomics applied to toxicology and pathology. Toxicol Pathol 2004; 32: 619-642

85 Kaput J, Rodriguez RL. Nutritional genomics: the next frontier in the postgenomic era. Physiol Genomics 2004; 16: 166-177

86 Waters MD, Olden K, Tennant RW. Toxicogenomic approach for assessing toxicant-related disease. Mutat Res 2003; 544: 415-424

87 Farland WH. Cancer risk assessment: evolution of the process. Prev Med 1996; 25: 24-25 